\title{
Hydrogen distribution and Passive Autocatalytic Recombiner (PAR) mitigation in a PWR-KWU containment type
}

\author{
Emma Lopez-Alonso, Davide Papini , Gonzalo Jimenez
}

\begin{abstract}
The evaluation of Passive Autocatalytic Recombiners (PARs) performance has been foreseen from the EU stress tests in the frarnework of a complementary and comprehensive review of the safety of the Nuclear Power Plants (NPPs). The study presented in this work analyses the size,location and number of the PARs to minimise the risk arising from a hydrogen release and its distribution in the containment building dur ing a hypothetical severe accident

A detailed 30 rnodel of a PWR KWU containment type was used for the simulations. The numerical tool is the GOTHIC 8.1 containrnent code, which can model certain aspects of the system geometry and beha viour in more detail than typically considered in containment performance analysis. The severe accident scenario chosen is a fast release of hydrogen steam mixture from hot leg creep rupture during SBO (Station Black Out) accident.

In the first place, the hydrogen preferential pathways and points of hydrogen accumulation were studied and identified starting from the base case scenario without any mitigation measure. Secondly, a con figuration of PARs was simulated under the same conditions ofthe unmitigated case. The number of PARs considered is 40 units distributed all over the containrnent building.

The PAR configuration offered an improvement in the chosen accidental scenario, decreasing the pos sibility of hydrogen combustion in all the containment compartrnents at the end of the transient The analyses showed that this PAR configuration could lead toa reduction between $3045 \%$ of the final hydro gen concentration. The hydrogen combustion risk is decreased with final hydrogen concentration values below the flamrnability limit (hydrogen concentration below 7\%). Nonetheless, the analysis showed the inability of the PARs to recombine in the early stage of the fast release (the first $12 \mathrm{~min}$ in this sequence), due to their inertia and occurrence of oxygen starvation conditions.
\end{abstract}

\section{Introduction}

The hydrogen production, distribution and combustion in a post-accident containment represent one of the most significant hazards for the containment integrity (Kljenak et al., 2012). The Passive Autocatalytic Recombiner (PAR) implementation is under study in many operating NPPs to reduce the hydrogen concentra tion during severe accidents, by converting the hydrogen into steam. This method is totally passive and requires studies that accurately predict the hydrogen pathways to ensure an unim paired PAR performance. The use of this technology is the most extensively deployed strategy to consume the hydrogen befare it could reach flammable concentrations during a severe accident, particularly during acddents with loss of electric power supply. The PAR implementation project was developed according to the known guidelines in severe accident management. Firstly, the 
IAEA TECDOC 1661 (IAEA, 2011) provided a guidance and support in severe accident management implementing various strategies regarding the hydrogen mitigation. These measures include the use of PARs for reduction of the hydrogen concentration. The TEC DOC also recommended the use of Computational Fluid Dynamics (CFD) and Containment 3D codes for hydrogen distribution analy sis. Secondly, the PARSOAR project was dedicated to hydrogen risk assessment in nuclear power plant containments, focusing on sev ere accidents and development of countermeasures (Bachellerie et al., 2003). The project elaborated a handbook aimed at guiding the implementation of hydrogen recombiners in nuclear power plants. Following the guidelines from these two references, it was possible to set a preliminary configuration of PARs in the containment.

After the number and location of these recombiners are defined, a demonstration of the efficiency of the PAR system installation is required by comparing the sequences with and without recombin ers, in order to quantify the reduction achieved in the combustion risk. A code with 3D capabilities is essential to simulate complex containment geometries.

To decide which tools are more appropriate for this task, the technical reports from the OECD/NEA have provided an exhaustive overview on the main simulation tools for hydrogen risk problems (NEA, 1999, 2015). The use of 3D containment codes has been widely extended for detailed containment mass and energy release simulations throughout the last years (Chen et al., 2011, 2012; Papini et al., 2011; Jimenez et al., 2015; Ozdemir et al., 2015a; Bocanegra et al., 2016; Xiao et al., 2016). In the named NEA reports, the use of a suite of tools such as a combination of a lumped parameter code, like MELCOR or MAAP, with a 3D containment code, like GOTHIC or GASFLOW, is highly recommended for hydro gen risk mitigation analysis.

Many researchers have used this combination of tools for hydrogen simulations in the past. Researchers from KIT performed comparative calculations between the LP code MELCOR and the 3D CFD code GASFLOW, calculating the hydrogen distribution in PWR KWU containment (Szabo et al., 2012, 2014). Several studies per formed by Grgić et al. (2012, 2014a,b) for PAR implementation are based on this suite of tools for the simulations. Mass and energy sources are obtained using the MAAP code and a 3D GOTHIC containment model is used for predicting the hydrogen distribution. The NAI Company (developers of GOTHIC) performed an extensive analysis of the Fukushima I accident using MAAP5 as the source code and GOTHIC as the code to simulate the detailed response of the containment (Ozdemir et al., 2015b).

Breitung et al. proposed a methodology for hydrogen risk and mitigation analysis in SA scenarios using several codes, including GASFLOW (Breitung, 1997; Breitung and Royl, 2000; Royl et al., 2000; Xiao et al., 2016). This methodology consists of several steps that include the selection of limiting scenarios, hydrogen sources, distribution and mitigation, and, finally, analysis of combustion regimes. An evolution of this methodology was applied also in the licensing process of the EPR in the UK (HSE, 2011a, 2013; Dimmelmeier et al., 2012). In particular, the MAAP4 code was used as SA code, applying COCOSYS for cases that needed more detail. The authors used GASFLOW for the most penalising scenarios. Cases involving supersonic deflagrations or detonations were sim ulated with another code called COM3D.

Based on these references, CFD codes and/or containment codes with 3D capabilities are established as state of the art numerical tools for hydrogen risk analysis in nuclear power plant contain ment buildings.

In the present paper, the MELCOR code is used to obtain mass and energy sources to be implemented in a detailed 3D model developed with the GOTHIC code. On the one hand, GOTHIC is a containment code often used as lumped parameter code, but that offers also CFD like capabilities for subdivided volumes predicting the thermal hydraulic behaviour with the conservation equations of mass, momentum and energy for multi component, multi phase flow, and which can model certain aspects of the system geometry and behaviour in more detail than typically considered in containment performance analysis (EPRI, 2014). On the other hand, MELCOR is a lumped parameter and integrated code that simulates all the physical processes with hydrogen generation dur ing an SA and gives mass and energy sources of gases released to the containment (SNL, 2015). Lumped parameter codes can pro vide average hydrogen concentrations but they have inherent lim itations concerning the conservation of momentum between control volumes and turbulent mixing, therefore they are not sui ted for detailed hydrogen distribution and mitigation studies. As a conclusion, the utilisation of GOTHIC shows clear advantages compared to lumped parameter codes in terms of precision, and to CFD codes, mainly in terms of lower calculation costs thanks to the adoption of a relatively coarse mesh. The fair accuracy of GOTHIC coarse mesh models has been demonstrated with a num ber of experimental exercises, as the OECD/NEA PSI CFD bench mark (at the PANDA facility in Switzerland) (Andreani et al., 2015; Fernández Cosials et al., 2015).

The methodology for assessing the mitigation of the hydrogen risk via PARs is thoroughly presented in (Serrano et al., 2016), where it was applied to install the PARs in a BWR Mark III contain ment type. The methodology proposed by the authors establishes an accurate reference for analysing PARs installation within con tainment with specific application for BWR. In this paper, the four steps of the methodology for PARs sizing and location analysis are extended to a large dry PWR containment (namely KWU). A detailed 3D model representing the containment building of a PWR KWU is considered. A suitable severe accident characterised by the fast release of hydrogen is chosen for analysing the distribu tion of hydrogen and evaluating the PAR implementation process. A preliminary configuration of PAR layout is described and the cor responding effectiveness in reducing the combustion risk is quantified.

\section{Methodology for PAR analysis}

The methodology for PARs installation analysis is divided into four steps: step 1 selection of the scenario simulated with the severe accident code MELCOR to obtain mass and energy sources; step 2 development of a 3D containment model with the GOTHIC code; step 3 hydrogen distribution analysis in containment; step 4

PAR location, implementation and analysis of efficiency (Serrano et al., 2016). The methodology is described and summarised in the diagram of Fig. 1, showing the sequence of each step in the PAR implementation and location process.

\subsection{Step 1: Hydrogen limiting sequence}

The severe accident scenario considered is a total Station Black Out (SBO) with high temperature creep rupture of the hot leg, which produces a fast release of a mixture of steam and hydrogen. The scenario was chosen to study the containment behaviour after a fast gas release, considered as the limiting sequence regarding the hydrogen combustion risk in containment. The fast release means that the gases from the primary system are injected in few seconds to the containment.

Mass and energy sources were obtained with MELCOR code. Arbitrary but conservative assumptions are made when simulating the transient. The hydrogen mass implemented in the GOTHIC sim ulations was twice the amount calculated with MELCOR. A total of $312 \mathrm{~kg}$ of hydrogen is released (considering only the in vessel 


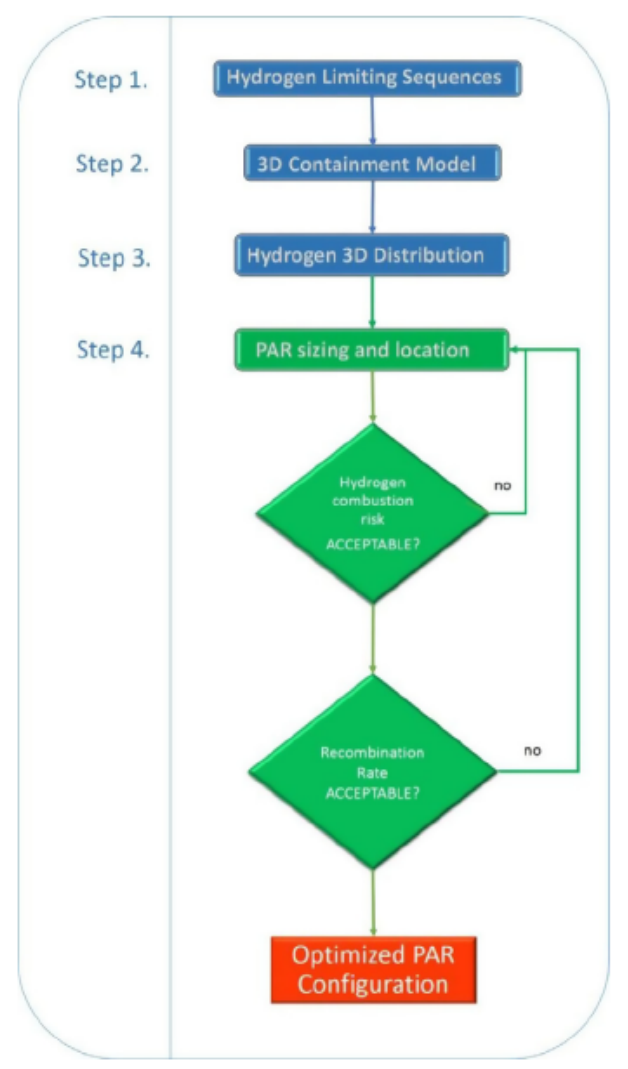

Fig. 1. PAR implementation methodology chart (Serrano et al., 2016).

phase of the severe accident, included a $100 \%$ safety margin). The large initial pressure difference between the primary circuit and the containment leads to choked flow, which produces an under expanded, sonic, high velocity jet into the break compartment. The dynamics of the fast release was calculated according to the critical flow limitation (choked flow model) available in GOTHIC (more details can be found in (Papini et al., 2015a)). Fig. 2 depicts the flow rate discharged through the break with a composition of $40 \%$ hydrogen and $60 \%$ steam. The initial steam concentration in the containment atmosphere is $45 \%$ due to previous releases of the pressurizer relief valves. The analysis considered only the first $1000 \mathrm{~s}$ of the transient, focusing on the jet release and mixing. A double ended guillotine rupture was assumed.

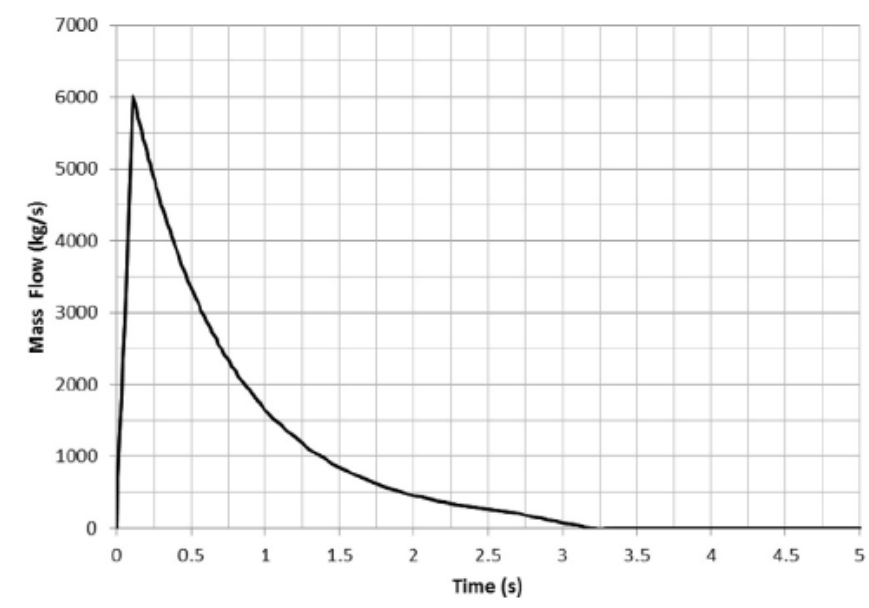

Fig. 2. Mass flow rate through the break implemented in the GOTHIC model, as calculated according to a best-estimate choked flow model.

\subsection{Step 2: 3D containment model}

The PWR KWU containment is a steel spherical containment (large dry PWR containment) surrounded by a concrete shell with annular gap. The GOTHIC model represents only the inner spherical part of the containment (filled with air), which is highly compart mentalised. The main feature of a PWR KWU containment is an internal cylindrical structure (named cylindrical shielding wall or missile protection cylinder), which envelops the primary system components and related compartments (component room). The steam generator towers represent the main hydraulic connections between the component room and the large open space above the upper deck including the dome (operating room).

A detailed 3D model of a PWR KWU containment type was used for the simulations. The model has to be capable of simulating mass and energy discharges within the containment and take into account heat transfer, steam condensation and turbulence effects. The version 8.1 of the GOTHIC code was applied (EPRI, 2014).

The GOTHIC model consists on the whole of 40 control volumes and the selected modelling approach is a compromise between a fully 3D representation of the entire geometry and a schematiza tion into convenient multiple subdivided volumes. More precisely, two large 3D subdivided volumes with full 3D geometry represent, respectively, the lower inner compartment where the break takes place (Vol. $17 \mathrm{~s}$ ) and the upper section with the dome (Vol. $1 \mathrm{~s}$ ). Details are depicted in Fig. 3. The other 15 large volumes model the geometry with 3D prisms (real height and equivalent cross sectional area), while the remaining volumes are lumped volumes. This type of modelling allows having a more detailed mesh in those regions of interest, such as the break zone. The position of the break is shown with a red circle in Fig. 4 and corresponds to the hot leg in one of the three loops, below the lower deck level. The impulse of the jet can be modelled properly choosing the mesh size in the vicinity of the injection similar to the injection size. The cell dimension is of the order of the hot leg diameter $(\sim 0.81 \mathrm{~m})$, with a coarsening in the upper containment volume $(\sim 1.62 \mathrm{~m}$ in Vol.1 s, see Fig. 4).

The complete model is composed of $\sim 37,000$ cells and 171 ther mal conductors (heat structures) that model the heat capacity of the structures and the heat transfer between the fluid and these structures. Molecular and turbulent diffusion (the $\mathrm{k} \varepsilon$ turbulence model is used) are considered and a second order accuracy in the spatial discretization of the advection terms is adopted, as recom mended for gas transport phenomena (Papini et al., 2015b).

\subsection{Step 3: 3D hydrogen distribution}

The 3D model described in step 2 is used for the analysis of the hydrogen distribution, considering the scenario selected in step 1. The analysis allows determining as accurate as possible the prefer ential hydrogen pathways along the containment and the points of accumulation that are of interest for the recombiner location. These pathways and points of accumulation were studied on the basis of a base case scenario without any mitigation measure sim ulated by (Papini et al., 2015a,b).

The steam generators and PRZ rooms were identified as the most likely hydrogen pathways because they offer a direct connec tion from the lower part of the containment, where the discharge takes place, to the dome section. Fig. 5 illustrates the hydrogen dis tribution in the entire containment (Fig. 5(a)) and in the inner compartmented room (Fig. 5(b)) in the first second of the transient.

The hydrogen produces a sonic jet that reaches the containment dome in less than $1 \mathrm{~s}$ and creates vortices as a result of its deflec tion on the spherical containment liner and walls (Fig. 6(a)). Fur thermore, the hydrogen immediately diffuses and fills the lower compartment on its way to the dome through the steam generator 


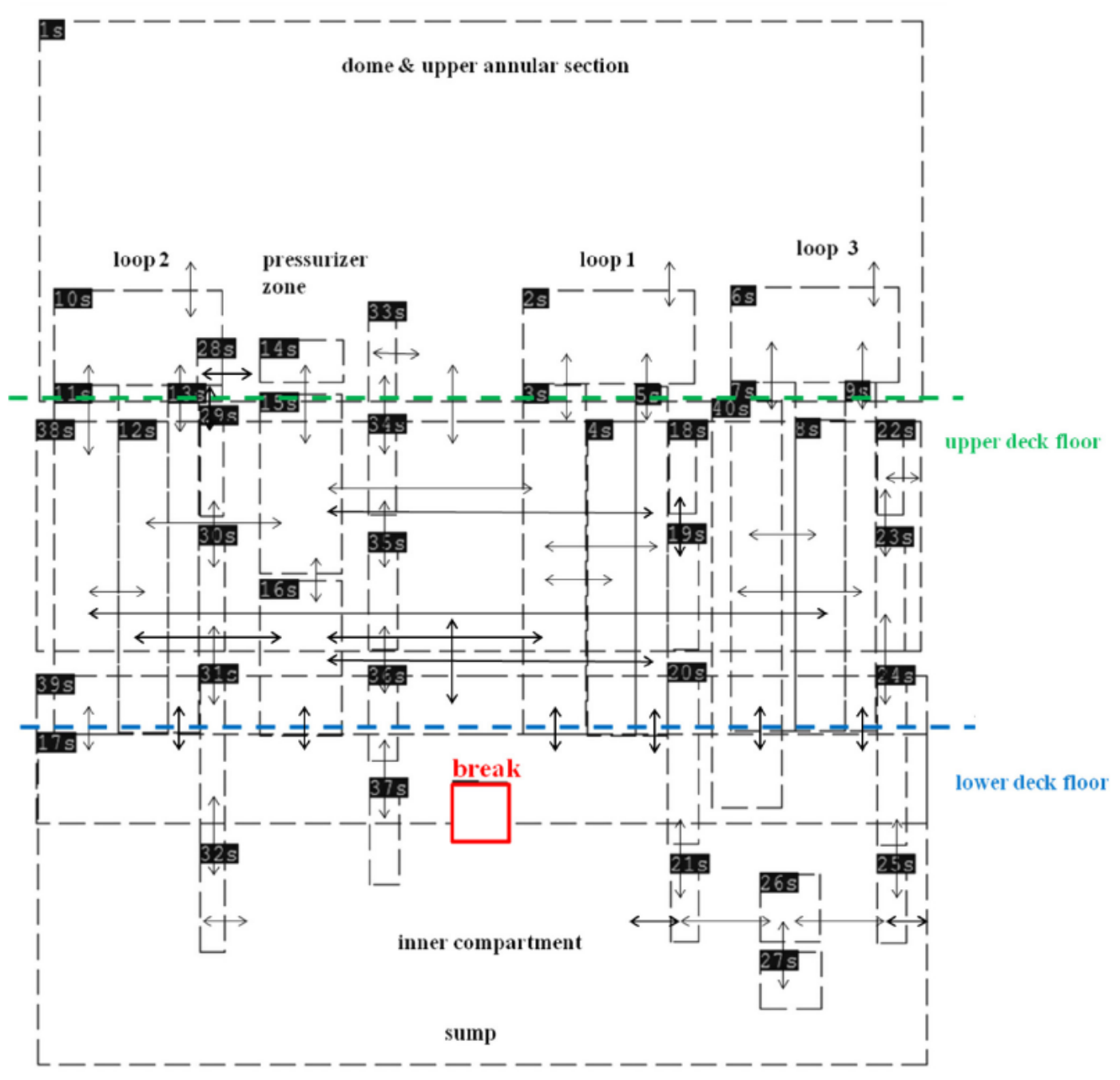

Fig. 3. GOTHIC nodalization diagram of the containment.

towers (Fig. 6(b)). Less affected by the jet is the steam generator opposite to the break. The overpressure induced by the jet lifts the dampers (flaps opening on top of the steam generator towers based on pressure difference) in all the three steam generator towers.

The convective mixing of hydrogen induced by the jet is the main phenomenon that can be observed during the first $10 \mathrm{~s}$ (Fig. 6(a)). In the early stages of the transient, turbulence plays a fundamental role on the hydrogen behaviour and quickly a strati fied cloud of hydrogen begins to form at the top of the containment (Fig. 6(b)). In about one minute, the hydrogen concentration sta bilises and a maximum of $15 \%$ is reached in the dome. Peak values are observed in the jet region but they never exceed $20 \%$ and per sist locally only for few seconds (Fig. 6(c)). A buoyancy driven hydrogen flow is established in all the containment and a stratified atmosphere is clearly visible (Fig. 6(d)). Another physical process occurs inducing a downwards flow, which reduces the hydrogen concentration in the dome by mixing and makes the stratified cloud gradually dissipate. The reduction of the hydrogen concen tration by this phenomenon is clearly visible in Fig. 6(d). This find ing is consistent with the simulations performed by (Royl et al., 2000) using the GASFLOW code. They defined this mixing phe nomenon as a condensation sedimentation effect, which acts as a mechanism of homogenization thanks to the wet atmosphere established in the dome.
Fig. 7 shows the hydrogen concentration in the two main large volumes: the upper volume with dome (Vol. 1 s) and the lower compartment (Vol. $17 \mathrm{~s}$ ). The average concentration at the end of the transient in the dome region is $7.5 \%$, whereas the local concen tration reaches $8.8 \%$. In the lower compartment, the average con centration remains around $2 \%$ as well as the local value. There is a significant difference between local (cell on top of the volume) and average value, especially in the upper volume. The average concentrations are useful for comparison with the prediction of LP codes, which would be capable of simulating mixed conditions at the end of the transient, however missing the heterogeneous conditions at the early stage of the scenario. Hereafter the gas con centrations will be expressed as local values, which represent bet ter the 3D phenomena involved.

The potential for combustion risk is evaluated on the basis of Le Chatelier's principle, based on the Shapiro diagram (Shapiro and Moffette, 1957), to determine the ignition threshold using the burn ranges and flammability limits from the MELCOR code (SNL, 2015). The hydrogen deflagration limit is set to $7 \%$ of hydrogen concentra tion and the detonation limit to $14 \%$. Furthermore, to ignite the mixture a minimum of air concentration of about $30 \%$ is required, whereas steam concentrations greater than $55 \%$ make the contain ment atmosphere inert. Fig. 8 plots the gas species concentration in the upper containment with the dome (Vol. 1 s) and the lower compartment (Vol. $17 \mathrm{~s})$. 

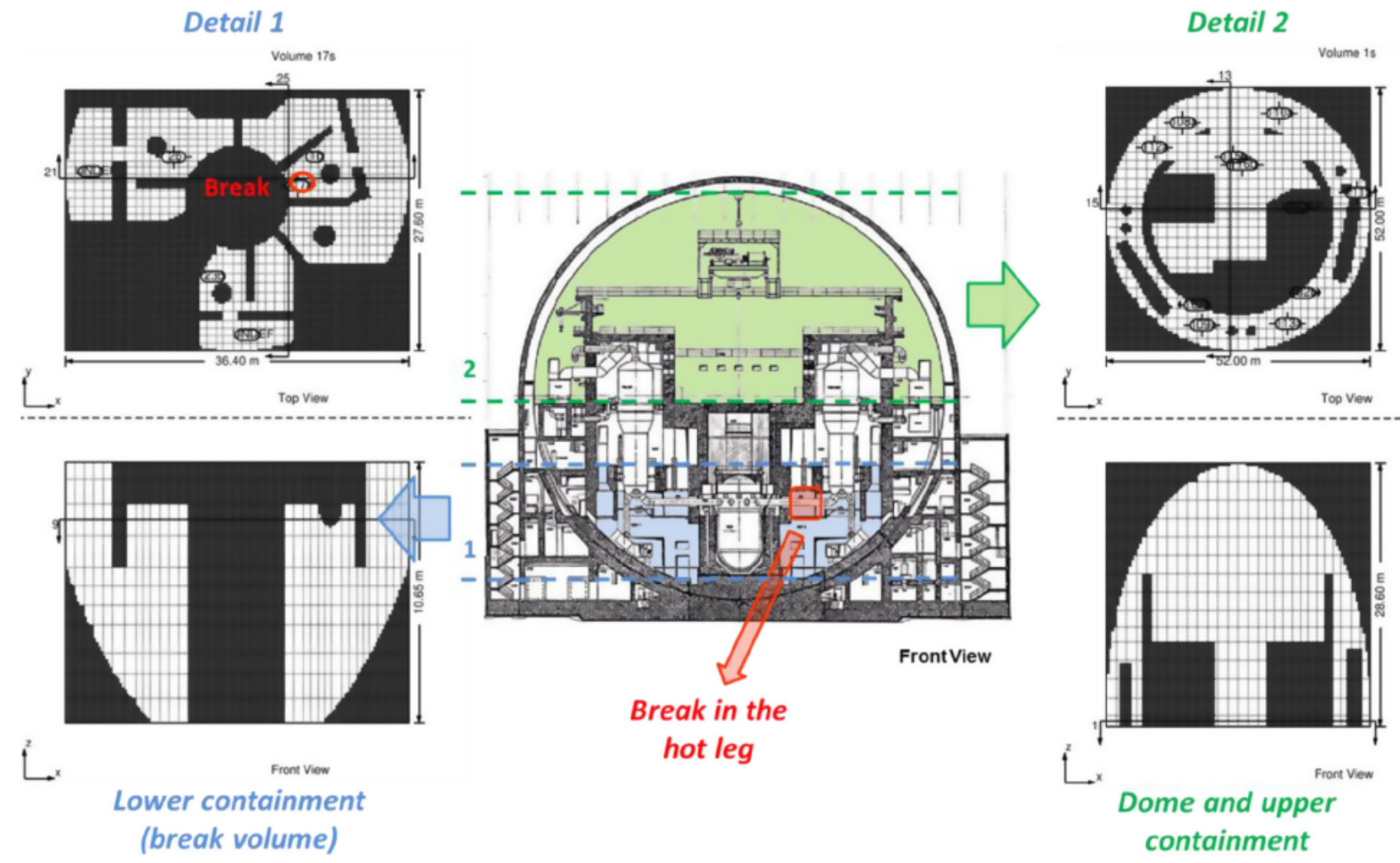

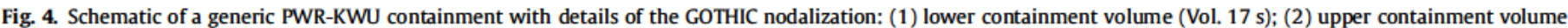
(Vol. 1 s) (Papini et al., 2015b).

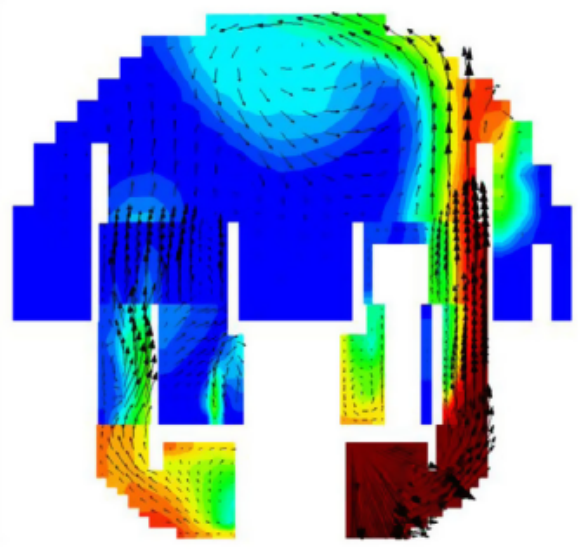

(a)

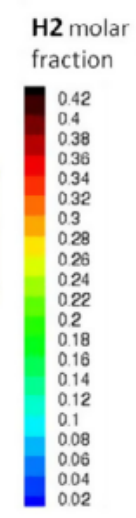

$\begin{aligned} & \mathrm{H} \text { molar } \\ & \text { raction }\end{aligned}$
0.42
0.4
0.38
036
0.34
0.32
0.3
0.28
0.26
0.24
0.22
0.2
0.18
0.16
0.14
0.12
0.1
0.08
0.06
0.04
0.02

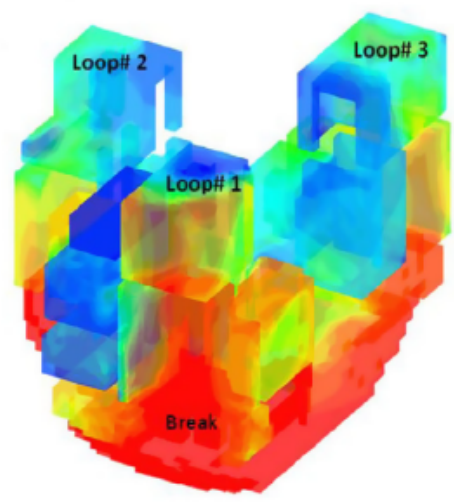

(b)

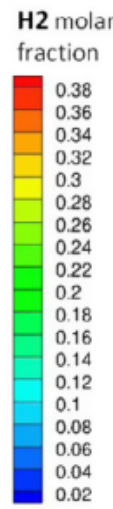

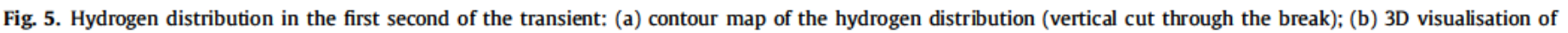
hydrogen diffusion in the lower compartment, excluding the large upper volume.

On the account of the considerations above, the combustion risk can be excluded just for the initial jet (first seconds of the simula tion). The high hydrogen concentrations in the gas mixture (up to $40 \%$ at the break point) are sufficiently diluted by high steam con tent (steam volume fraction above 55\%). At the beginning of the scenario, the jet displaces the atmosphere in the lower part of the containment preventing the combustion risk (oxygen volume fraction almost null, see Fig. $8($ b)). However, when the air is restored in the inner compartment and overall due to steam con centrations in containment below the extinction limit, flammable conditions are established and the risk of hydrogen combustion increases (Papini et al., 2015a,b).

\subsection{Step 4: PAR sizing and location analysis}

The PARs implementation process starts by choosing the size of the recombiners according to the recombination rate and the space available within the containment. The PAR location is based on the more likely hydrogen pathways obtained from the distribution analysis of step 3. After the number and location of the recombiners are defined, a demonstration of the efficiency of the PARs system is carried out by comparing the selected sequence (step 1) with and without recombiner mitigation. As part of the PARs sizing and loca tion analyses, the recombination rate of each PAR implemented in the model was analysed in order to determine whether the recom 


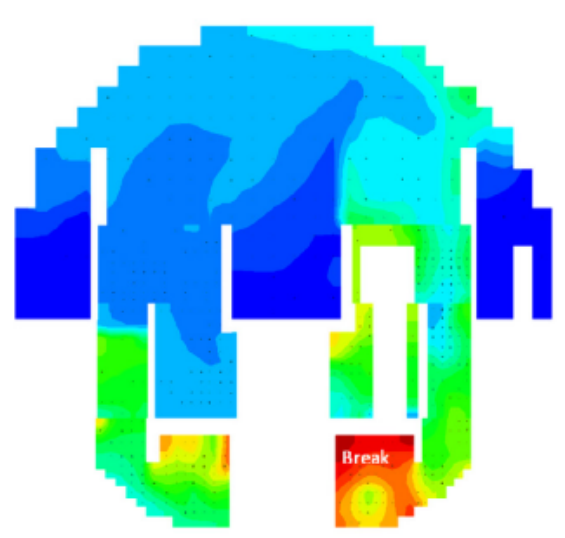

(a) $10 \mathrm{~s}$

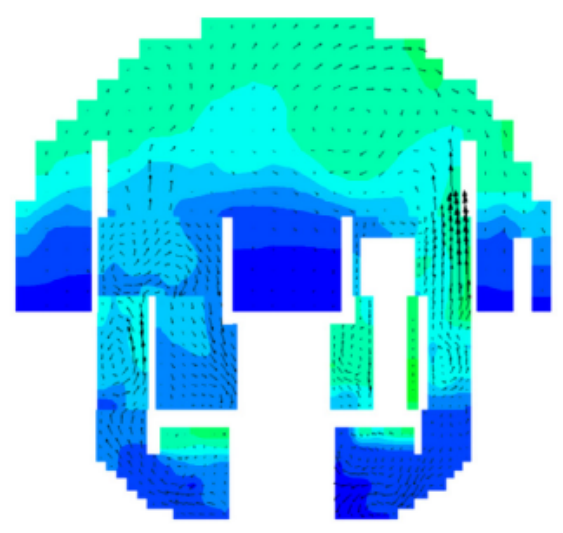

(c) $60 \mathrm{~s}$

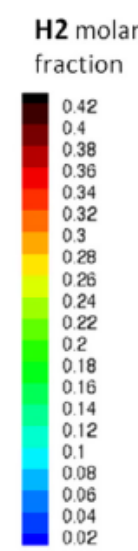

H2 molar fraction
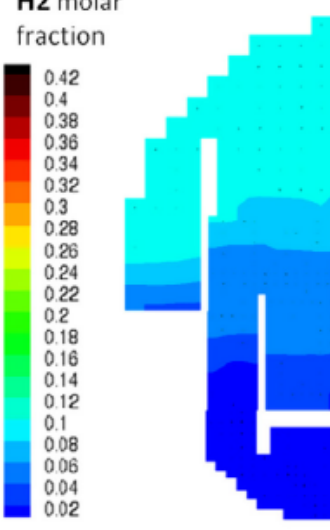

H2 molar

fraction

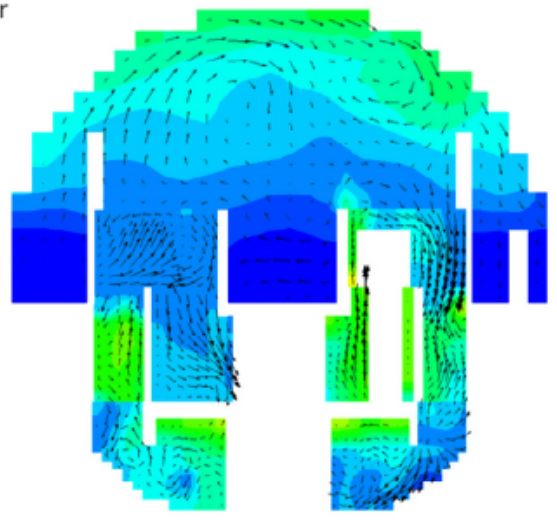

(b) $30 \mathrm{~s}$

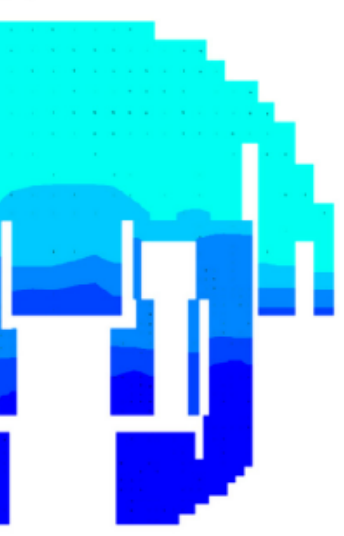

(d) $1000 \mathrm{~s}$

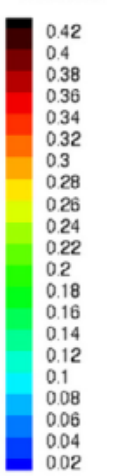

H2 molar fraction

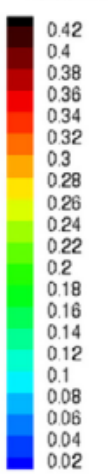

Fig. 6. Contour maps of hydrogen distribution in time (vertical cut through the break).

biner was properly placed. Alternatively, the PAR should be relo cated in another containment section to increase its efficiency, and, on this basis, optimise the PAR configuration.

\subsubsection{PAR performance and modelling}

Most of the PAR designs use rows of vertical catalytic plates with platinum and palladium on ceramic washcoat housed inside a metallic structure. The PAR performance is given by the oxidation of the hydrogen by the oxygen available in the inlet gas flow, with the use of metals as a catalyst. This method is totally passive and requires studies that accurately predict the hydrogen pathways and 3D distribution.

The PAR performance is characterised by a depletion rate func tion that depends on pressure and hydrogen concentration. The GOTHIC code has a built in component to model the PARs, which reproduces the effects of the hydrogen recombination (i.e., the con version of hydrogen into steam according to the balanced chemical reaction: $2 \mathrm{H}_{2}+\mathrm{O}_{2} \rightarrow 2 \mathrm{H}_{2} \mathrm{O}$ ) for the flow path (a 1D flow junction) on which the PAR is placed. The PAR component recombines the hydrogen $\left(\mathrm{H}_{2}\right)$ provided that enough oxygen $\left(\mathrm{O}_{2}\right)$ is flowing in the respective flow path, with the amount of hydrogen recombined that is limited stoichiometrically. The characteristics of the metal lic box are not modelled and the global effects of the PAR operation are introduced as mass, energy and momentum source in the downstream cell. The heat from the recombination reaction, together with the vertical arrangement of the catalyst plates, pro motes a buoyancy flow by natural convection. The buoyancy force is calculated by the recombiner model as a function of the density variation and introduced as momentum source for the vapour gas mixture (EPRI, 2014).
The PAR efficiency, defined as the recombination rate divided by the inlet hydrogen mass flow rate, is simulated in the PAR compo nent with an external function (Dynamically Linked Library, DLL), which is implemented in the GOTHIC model by means of control variables (one control variable for each PAR), called every time step. The use of the DLL function was proposed by the code devel opers (NAI). The control function implements the Areva propri etary recombination rate formula; the mathematical formulation of the Areva PAR formula was published in the open literature by Visser et al. (Visser et al,, 2013) (they modelled the Areva Siemens PAR type FR90 150 as considered in two selected experi ments in the THAI facility). Going more into detail, the PAR deple tion rate function is based on the following GOTHIC variables: pressure, hydrogen and oxygen molar fractions, vapour and hydro gen densities (defining the hydrogen mass fraction in the inlet flow), and the vapour flow in the flow path where the PAR is located. The function output is the PAR efficiency, used by the code to compute the PAR recombination performance.

A dynamic model of the effect of the PARs requires a mesh size of the order of the PAR dimensions, in order to accurately simulate the local conditions of the thermal plume at PAR outlet and respec tive mixing. This condition is respected in the used GOTHIC model (step 2), which has a maximum cell size (in the dome) of $2 \mathrm{~m}$ (PAR height, according to vendor data, is $1.4 \mathrm{~m}$ ). The PAR model, based on the Areva formula implemented as an external function, has been verified by matching the nominal recombination rate in the conditions specified by the vendor (uniform $\mathrm{H}_{2}$ concentration of $4 \%$ and pressure of $1.5 \mathrm{bar}$ ). The qualifications of the PAR model focused on validating with experimental data the consistency and physically sound behaviour of the GOTHIC component as 


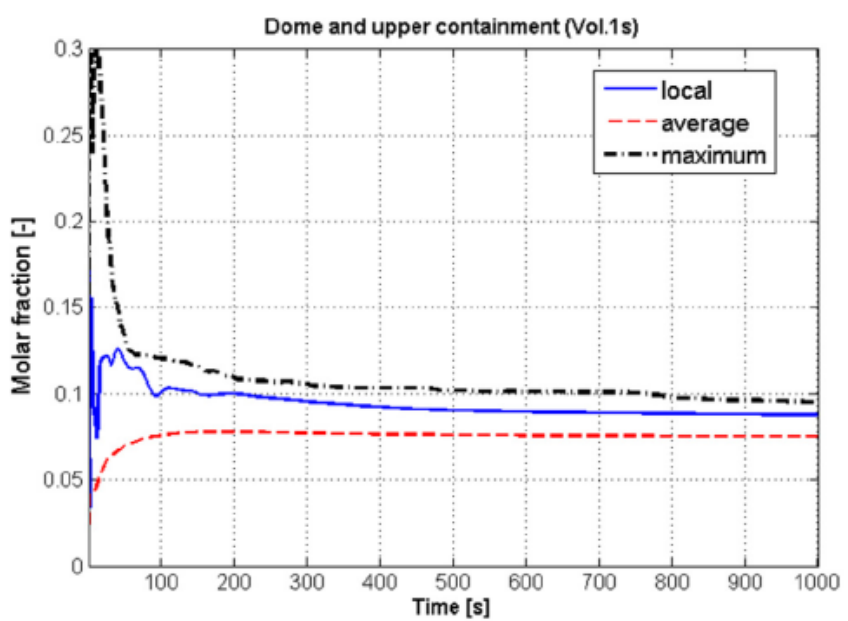

(a)

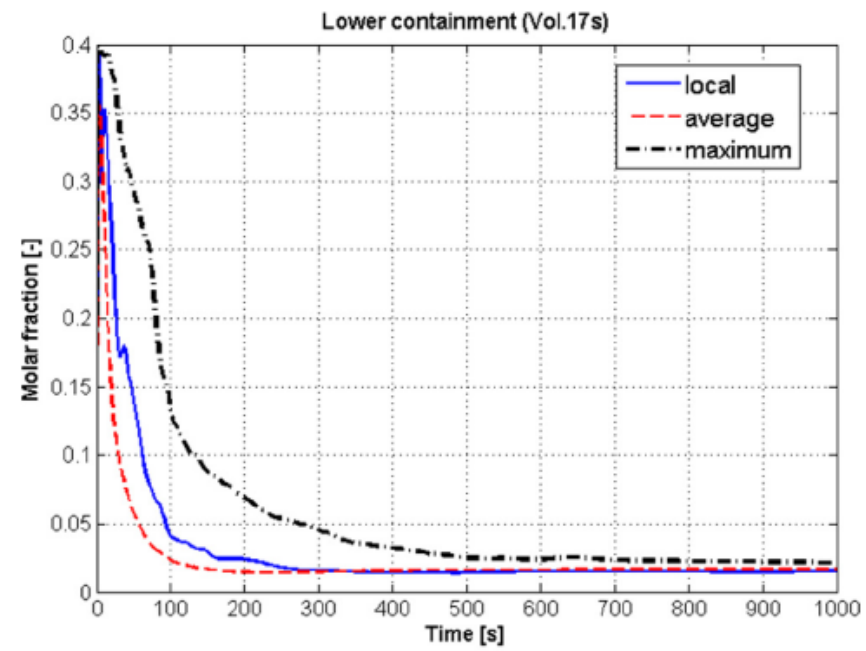

(b)

Fig. 7. Local (cell on top of the volume), average and maximum hydrogen concentration in (a) upper containment with dome (Vol. 1 s) and (b) lower compartment (Vol. $17 \mathrm{~s}$ ).

embedded in a representative mesh and under the flow conditions of interest for the fast release scenario are not discussed in this paper.

\subsubsection{PAR sizing and location}

The first criterion followed for the selection of the PAR was the expertise provided by Visser et al. (Visser et al., 2013) for the FR90 150 Areva Siemens recombiner. Some sensitivity analyses were performed regarding the size of the recombiner. On the account of the criteria proposed by (Bachellerie et al., 2003), the large PAR Areva Siemens FR1 1500T is chosen to mitigate the accident scenario (AREVA, 2011). This type of PAR, the biggest on the Areva catalogue, offers the highest recombination rate. A smaller PAR should be installed in case the space available in the containment would not be enough.

The PAR configuration is obtained from the hydrogen preferen tial pathways and accumulation points studied in step 3. This con figuration is expected to reduce the combustion risk of hydrogen within acceptable limits, and assure that each recombiner fulfils the vendor specifications for the recombination rate. A preliminary PAR configuration is analysed on the basis of the methodology extracted from the (IAEA, 2011) document, focused on the hydro gen mitigation during a severe accident. This document recom

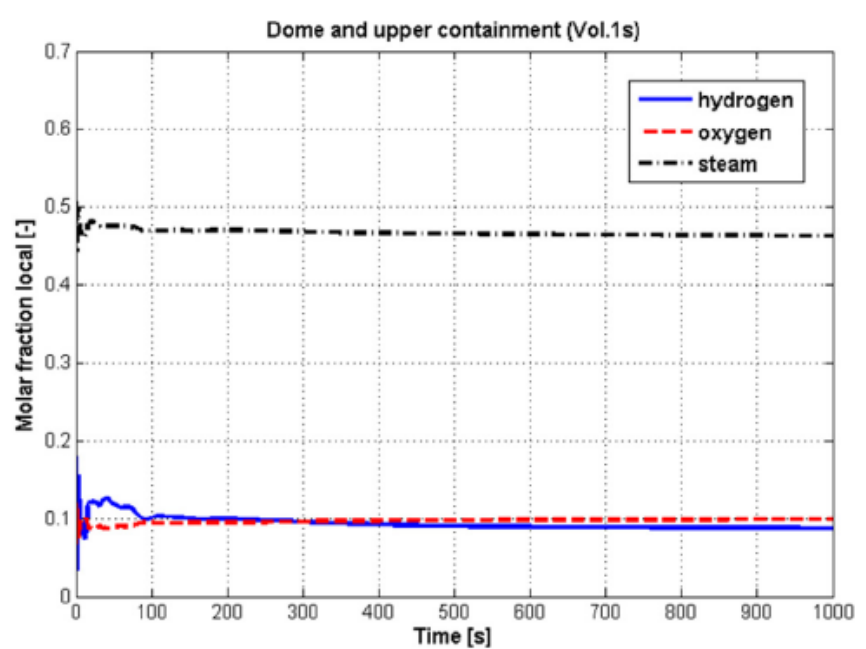

(a)

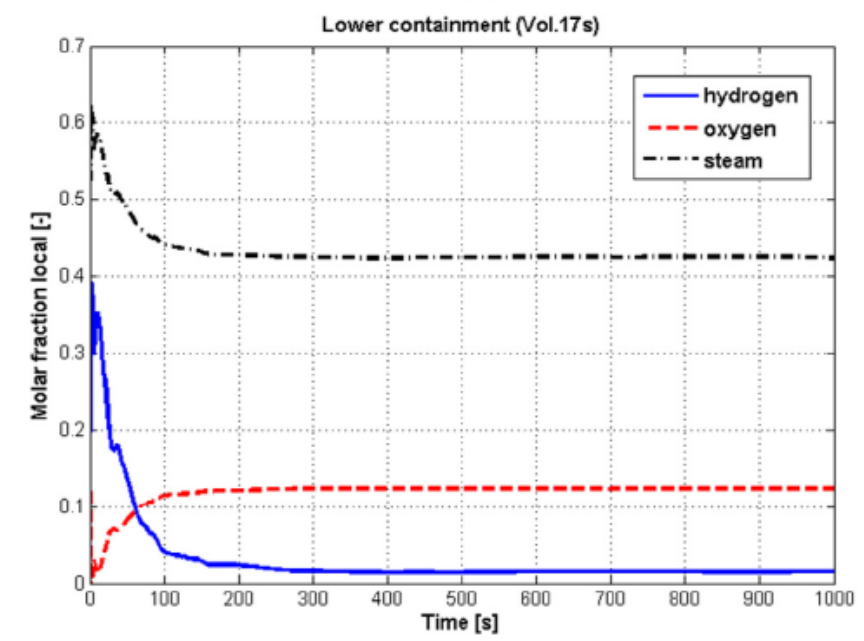

(b)

Fig. 8. Gas concentrations in (a) upper containment with dome (Vol. $1 \mathrm{~s}$ ) and (b) lower compartment (Vol. $17 \mathrm{~s})$.

mends the installation of 40 units for a large dry PWR containment, like the PWR KWU containment building.

The analyses of step 3 identified the steam generator and PRZ rooms, as well as the dome, as preferential regions of hydrogen flow and accumulation. The preliminary PAR configuration addressed consequently these zones. The PAR distribution in the dome region, with PARs attached to the cylindrical shielding wall, was defined with $30^{\circ}$ of separation (IAEA, 2011) (similarly to the criteria typically used for the igniters). Furthermore, some addi tional considerations were followed due to the harsh conditions of the fast release scenario (mainly in terms of high temperature of the gas mixture).

The reference PAR configuration chosen for the analysis consists in 40 PARs distributed all over the containment enclosures: namely, 21 units placed in the dome region, 15 units placed in the steam generator towers, and 4 units located in the lower part of the containment. Fig. 9 represents a schematic vertical cut of a generic PWR KWU containment type showing the layout of the PAR configuration considered.

\subsubsection{Safety demonstration analysis}

The efficiency and the reduction of the combustion risk for the PARs system installation were demonstrated by comparing the 


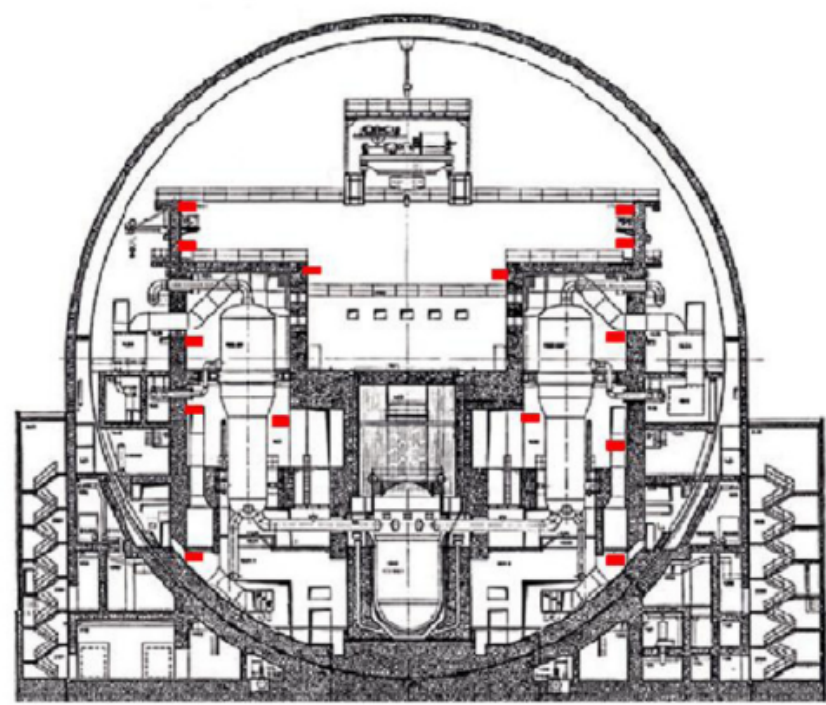

Fig. 9. Schematic with a vertical cut of a generic PWR-KWU containment type showing the PAR configuration chosen.

mitigated scenario with the unmitigated scenario, using the data provided by the previous steps.

In the $1000 \mathrm{~s}$ of transient simulated, the recombiners imple mented were able to reduce the hydrogen concentration between $30 \%$ and $40 \%$ in the different control volumes. Fig. 10 shows the hydrogen concentration in the most representative control vol umes: the upper containment with dome (Vol. $1 \mathrm{~s}$ ) and the steam generator tower of loop 1, below which the hydrogen discharge takes place (the compartmented room corresponding to a steam generator is modelled with three subdivided control volumes suit ably connected, Vol. $2 \mathrm{~s}$, Vol. $3 \mathrm{~s}$ and Vol. $5 \mathrm{~s}$, respectively, for loop 1 ). The final hydrogen concentration was $8.8 \%$ in the upper con tainment (Vol. $1 \mathrm{~s}$ ) for the unmitigated scenario, whereas in the mitigated scenario the final concentration diminished to $5.5 \%$. The PARs installed in the dome section are able to consume almost $40 \%$ of the hydrogen due to their higher recombination rate. The hydrogen concentration in the steam generator 1 platform area (lateral zone above the grating connecting to the lower contain ment volume) (Vol. $5 \mathrm{~s}$ ), main section housing the steam generator body (Vol. $3 \mathrm{~s}$ ) and top area with steam generator head (Vol. $2 \mathrm{~s}$ ) are also reduced by $30 \%$ and $45 \%$.

Fig. 11 depicts the difference in the final hydrogen concentra tion throughout the containment in both cases: unmitigated (Fig. 11(a)) and mitigated (Fig. 11(b)) scenario. The hydrogen dis tribution in the dome is controlled by flows and steam condensa tion on the concrete and steel structures. The lower part, between the cylindrical shielding wall and the steel shell, repre sents a region of low circulation, where the atmosphere remains stratified in the unmitigated scenario (Fig. 11(a)). On the contrary, in the mitigated scenario, the PARs performance mixes the atmo sphere in the containment dome so that the light gas propagates to the bottom, increasing slightly the hydrogen concentration in this region (Fig. 11(b)).

The proposed preliminary PAR configuration was capable of fac ing a considerable amount of hydrogen by reducing the hydrogen concentration below the $7 \%$ (identified as the deflagration limit) in all the control volumes. Nonetheless, this configuration offers a partial mitigation solution, since sudden and significant hydro gen release such as in the scenario simulated is difficult to be con trolled, independently of the number of recombiner installed. It would be necessary to rely on the mixing induced by the large free volume (mainly in the containment dome) at the early stage or on

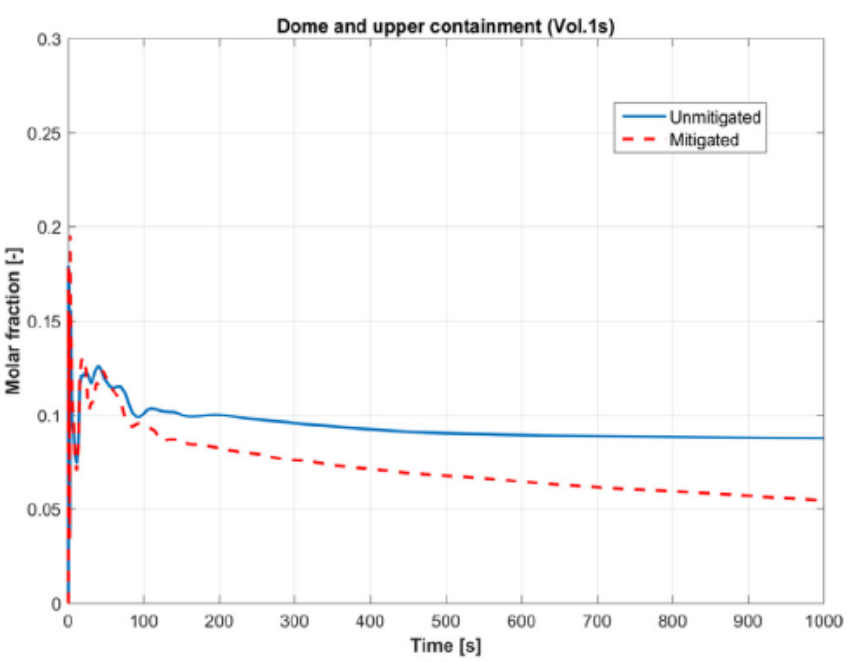

(a)

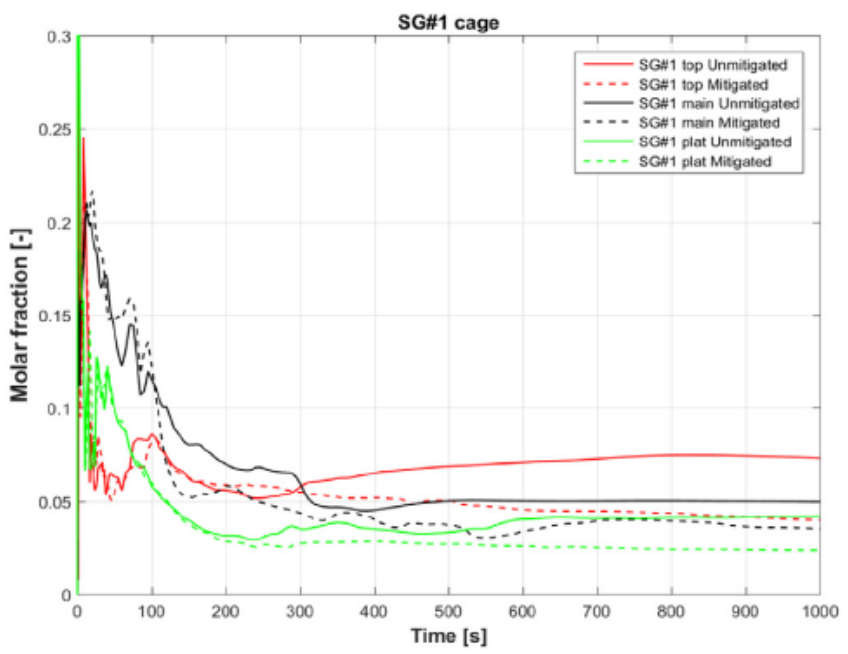

(b)

Fig. 10. Local hydrogen concentration in the most representative control volumes: upper containment with dome (Vol. $1 \mathrm{~s}$ ) and the steam generator tower of loop 1 where the hydrogen discharge takes place (Vol. $2 \mathrm{~s}$, Vol. $3 \mathrm{~s}$ and Vol. $5 \mathrm{~s}$ ).

other mitigation techniques such as filtered venting for the rest of the transient.The analysis of the viability of the PAR configuration included the study of the oxygen consumption profiles (oxygen starvation) and the possibility for ignition of the gas mixture due to the PAR performance. The results of the noteworthy experi ments on the PAR behaviour at the THAI facility (NEA, 2010) pointed out that a high surplus of oxygen is required for an unim paired PAR performance. A minimum oxygen surplus factor $\Phi$ (defined as $2 C_{\mathrm{O} 2} / C_{\mathrm{H} 2}$, being $C$ the gas concentration) between 2 and 3 was prescribed from the test data for unimpaired PAR oper ation. Therefore, the oxygen concentration limits the recombina tion rate and a condition of oxygen starvation (for instance defined by the stoichiometric ratio $\mathrm{O}_{2}: \mathrm{H}_{2}$ of $1: 2$, i.e. $\Phi$ 1) signifi cantly reduces the PAR performance.

The fast hydrogen discharge is characterised by a displacement of the atmosphere, which reduces the oxygen concentration (See both scenarios: unmitigated (Fig. 13(a)) and mitigated (Fig. 13 (b))) and prevents the proper performance of the recombiners at the beginning of the transient with a $\Phi$ factor less than 1 and close to zero, as it could be seen in Fig. 12, in compartments such as the lower part or steam generator cage. The PARs start their nominal 


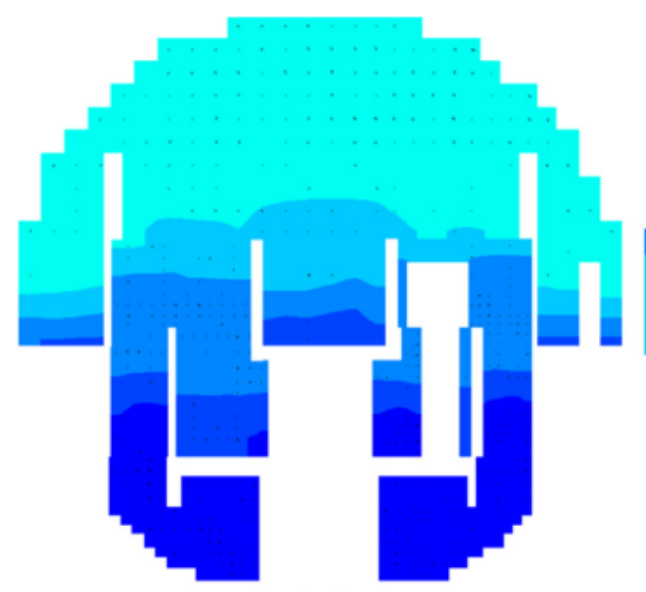

(a)

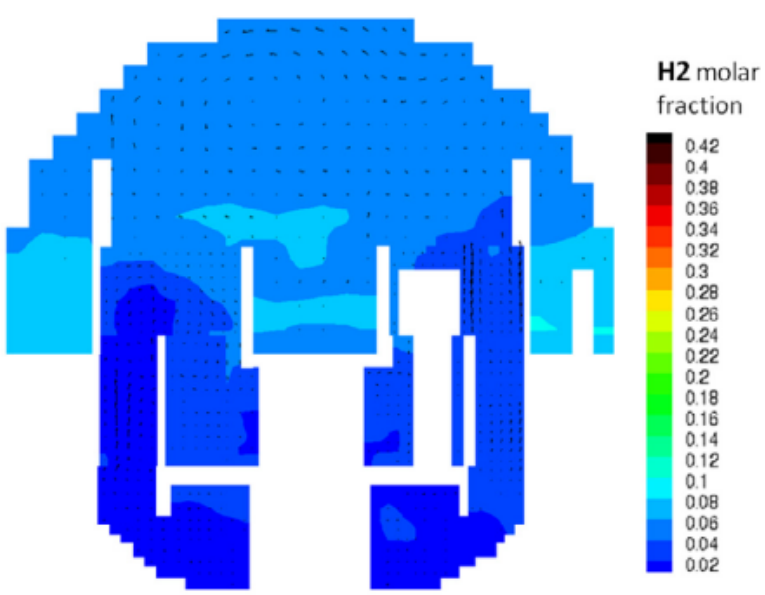

(b)

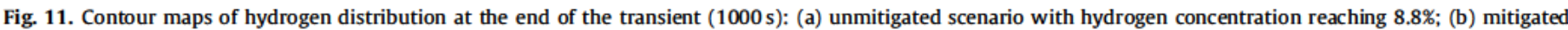
scenario reaching 5.5\%. This demonstrates the capacity of the PARs to reduce the hydrogen concentration.

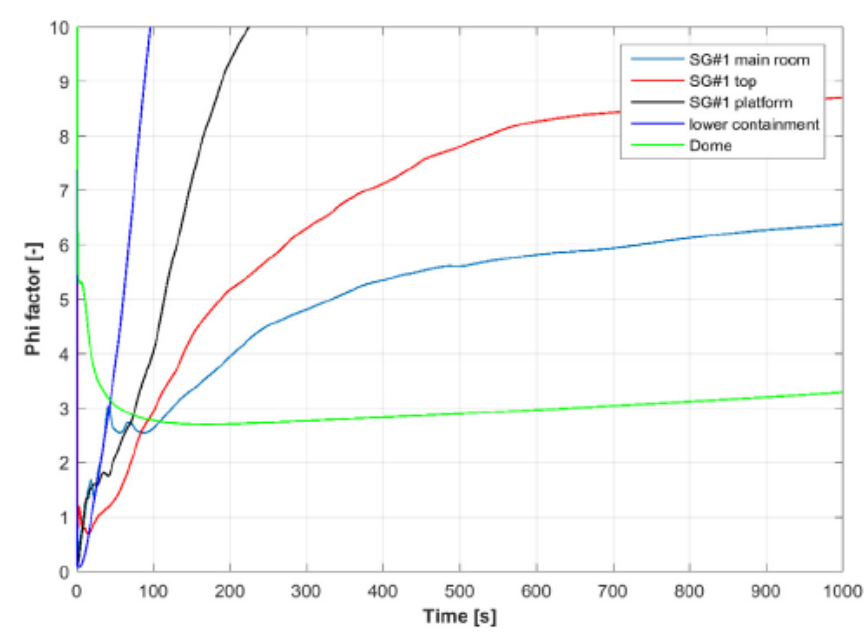

Fig. 12. $\Phi$ factor for the mitigated scenario in the main involved compartments. This factor helps to identify clearly and easily the conditions of oxygen starvation. At the early stages, the oxygen starvation makes the factor close to zero in the lower parts of the containment, rising once the oxygen is restored ( $>2-3$ ). In the dome, the factor reduces along the transient due to the recombiner performance.

performance once the air is restored and the oxygen surplus is recovered $(\Phi>23)$ at approximately $50100 \mathrm{~s}$ after the discharge. Furthermore, the oxygen concentration was reduced along the transient due to the PAR operation, visible in Fig. 13: unmitigated scenario (Fig. 13(c)) and mitigated scenario (Fig. 13) both at $600 \mathrm{~s}$.

\subsubsection{Hydrogen ignition by PAR}

The PAR operation leads to an overheating of the catalyst plates; the heat source produced by the recombiner activity can create local conditions for hydrogen combustion, as the igniters do. The severe accident analysed herein poses harsh conditions in contain ment, such as the high temperature of the gas released in the lower compartment (and rapidly reaching the upper compartments), the low oxygen concentration given by the atmosphere displacement induced by the jet, or the high steam concentration (high humid ity). The behaviour of the PARs under these conditions must be considered carefully in order to avoid impaired performance or even PAR failure.

Significant progress in knowledge on hydrogen behaviour and removal by PARs was achieved by the OECD THAI project, including a better understanding of the PAR ignition potential (NEA, 2010). Combining the findings from one specific test series (HR Hydro gen Recombiner series) on the minimum hydrogen concentration for ignition by PAR and those on the minimum oxygen surplus required for unimpaired PAR performance (and hence for maxi mum catalyst temperature that is correlated with ignition), a rela tively small area in the $\mathrm{H}_{2}$ Air Steam ternary diagram could be defined to which ignition by PAR is confined (Fig. 14(a)) (NEA, 2010).

Dewit et al. (Dewit et al., 1996) describe a recombiner model and the results from full scale tests carried out in the Large Scale Vented Combustion Test Facility at AECL WL. These tests con firmed the capability of the recombiner to operate under high humidity conditions and to perform unaffected after the operation at $700{ }^{\circ} \mathrm{C}$ in hydrogen and oxygen concentration of $20 \%$ and $6 \%$, respectively, as well as to endure $10 \%$ and $14 \%$ hydrogen burns without catalyst function impaired. Several experimental qualifica tion analyses have been carried out to verify the resistance of the PAR to high temperatures, in the range of $700800{ }^{\circ} \mathrm{C}$ (Bachellerie et al., 2003). Besides, those temperature limits were set considering the operation temperature range of the igniters, which is $800900^{\circ} \mathrm{C}$.

The external function defining the PAR efficiency in the GOTHIC model was modified according to these PAR limitations: the max imum hydrogen concentration that the PAR is capable of recom bining was set to $8 \%$, which corresponds to a catalyst plate temperature of $800^{\circ} \mathrm{C}$ (Bachellerie et al., 2003; NEA, 2010). In the simulations, the recombiner stops working when this temperature is reached (the PAR becomes inoperative with a processed gas tem perature higher than $800^{\circ} \mathrm{C}$ ).

The ignition of the PAR units was separately evaluated using a Matlab code to analyse if the recombiners could reach the ignition conditions, namely if the gases concentrations in the recombiner (in the same cell where the PAR is located) could lay inside the ignition area described above. The output of the analysis is repre sented on the Shapiro diagram in Fig. 14(b). The green triangle depicts the ignition area; blue diamonds represent the PARs out of ignition risk and red diamonds the PARs that at some time steps reach the ignition condition. The results show that thanks to the high steam content present in containment, none of the recombin ers reaches ignition potential (only selected time steps are drawn for a better visualisation). Despite the harsh conditions reached in this transient, the proposed PAR layout configuration poses no risk for the PAR to be a combustion source. It is mentioned that 


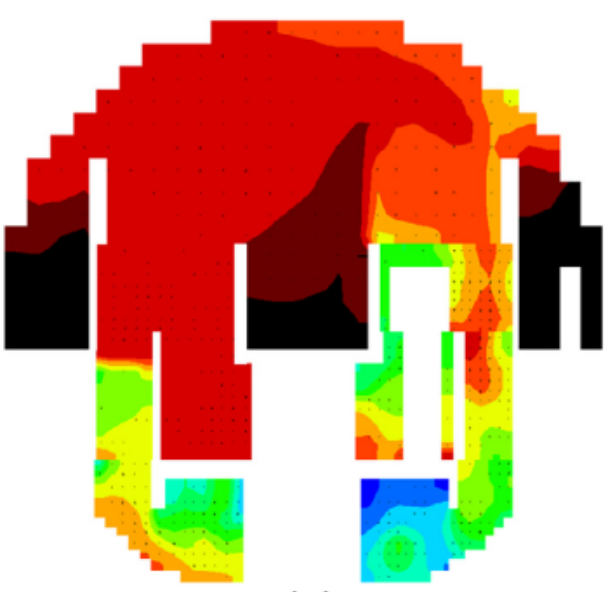

(a)

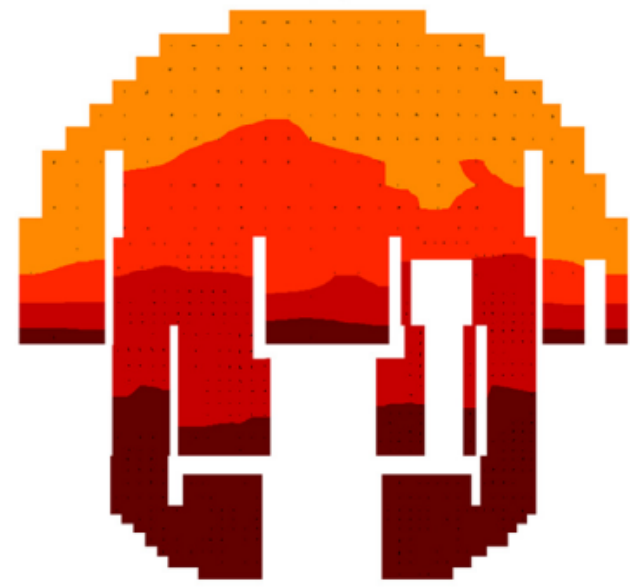

(c)

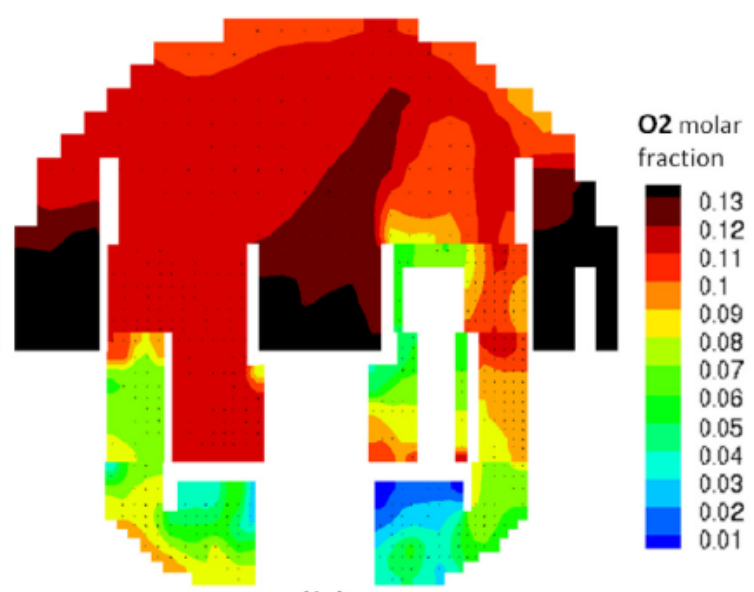

(b)

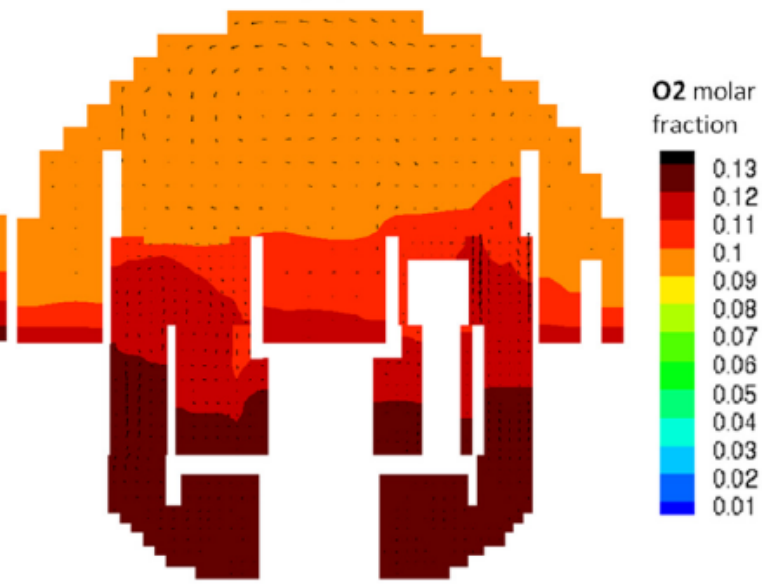

(d)

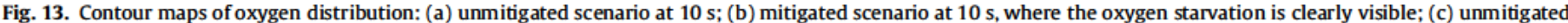
scenario at $600 \mathrm{~s}$; and (d) mitigated scenario at $600 \mathrm{~s}$ where the oxygen concentration decreases due to the PARs performance.

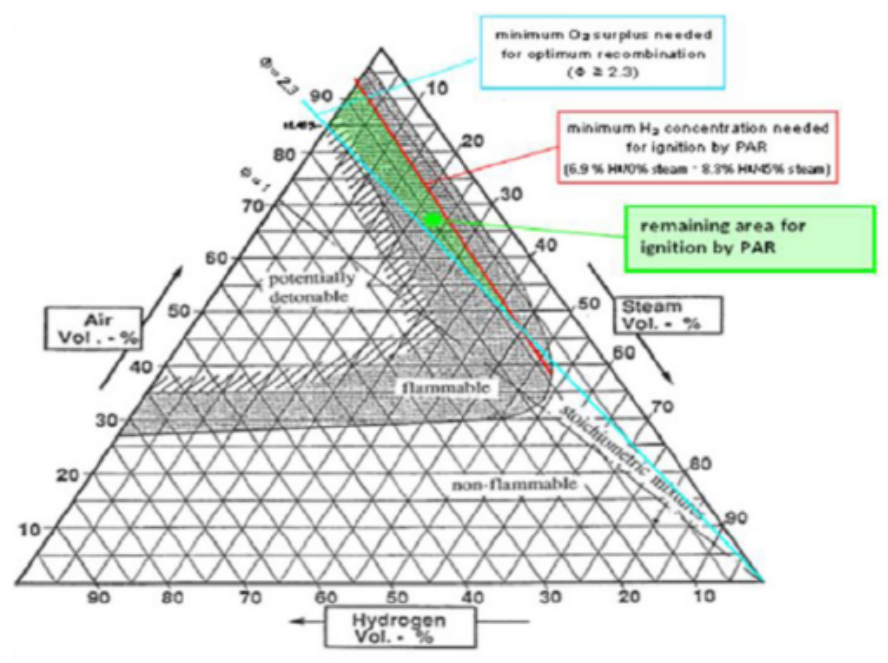

(a)

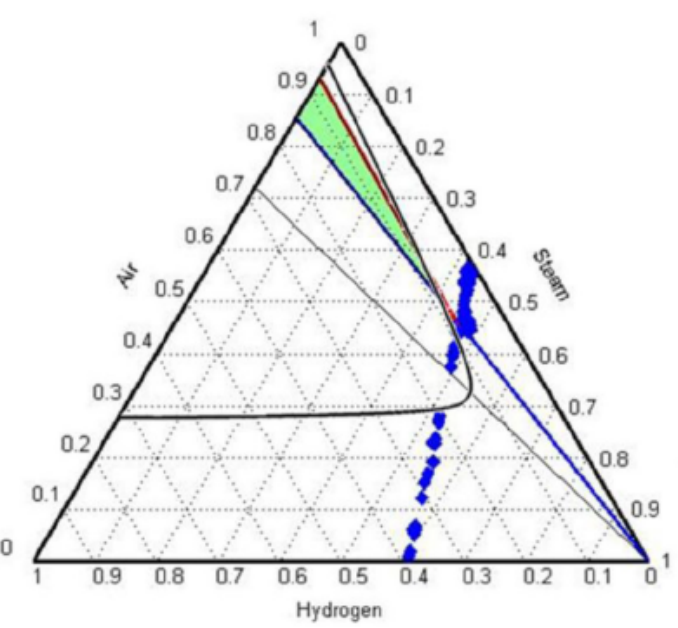

(b)

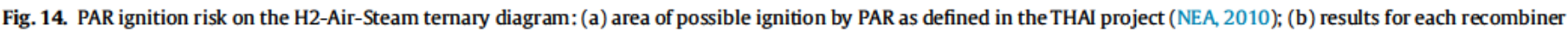
in the present study (only selected time steps are drawn for a better visualisation). The green triangle represents the area for which the PAR could reach ignition conditions. 
the analysis only considers the possibility of PARs as ignition source, but does not imply that there is no combustion risk (the flammability curve is still crossed at the early stage of the tran sient) or that there are no other ignition sources within the con tainment (given, e.g., by electrical cables or equipment).

\section{Conclusions}

The study presented in this paper applied a methodology for location, sizing and quantity of PARs to be installed in a PWR KWU containment building for minimising the hydrogen combus tion risk. The methodology is divided into four steps. The hydrogen discharge (mass and energy release) was evaluated with the MEL COR code for a total Station Black Out (SBO) accident with a fast release of steam and hydrogen mixture (step 1). A detail 3D GOTHIC model was used to analyse the hydrogen distribution and determine the preferential hydrogen pathways and areas of hydrogen accumulation along the containment (step 2 and step 3). The PARs implementation process addressed the preferential zones of hydrogen flow and accumulation, which were identified in the steam generator towers and the dome. The hydrogen accu mulates mostly in the dome due to its fast diffusion and rises to the upper part of the containment. Finally, a demonstration of the efficiency of the PARs system installation was performed by comparing the unmitigated and mitigated sequences (step 4).

A large PAR, the Areva FR1 1500T, was chosen for the simula tions according to recombination performance and space available in the containment. The recombiner performance was studied in depth, with emphasis on oxygen starvation conditions and PAR ignition potential. The PAR preliminary configuration consisted of 40 PARs distributed all over the containment enclosures: 21 units placed in the dome region, 15 units placed in the steam generator towers, and 4 units located in the lower part of the containment. The PARs can operate with the nominal rate only after the atmo sphere displacement induced by the fast hydrogen discharge is cleared and the conditions of oxygen starvation are excluded. The output of the analysis of ignition by PAR confirmed that the entire PAR fleet chosen is out of ignition risk, even under the tough condition simulated. The assessment of the ignition by PAR is important for the viability of a severe accident management based on this specific passive mitigation system and should be intro duced into PSA studies.

In view of the results, the PARs are demonstrated to offer an improvement in the chosen accidental scenario, decreasing the possibility of hydrogen combustion in comparison with the unmit igated case. The analyses showed that this PAR configuration could lead to a reduction of $3045 \%$ of the final hydrogen concentration. The hydrogen combustion risk is decreased with final hydrogen concentration values below the flammability limit (hydrogen con centration below 7\%). Nevertheless, it has been shown that the PARs are unable to recombine in the early period of the fast release (approximately quantified in the first $12 \mathrm{~min}$ in this sequence depending on the containment zone), due to their inertia and occurrence of oxygen starvation conditions, then failing to prevent completely the combustion risk for a limiting scenario with fast hydrogen release.

\section{Acknowledgments}

The authors want to express their deep gratitude to the Labora tory for Thermal Hydraulics (LTH) of Paul Scherrer Institut (PSI) where the work has been performed in the framework of a GENTLE "Student Research Experience" (Accepted Proposal N.15). GENTLE is a Coordination and Support Action in the 7th Framework Pro gramme of the European Atomic Energy Community (Grant Agree ment Number 323304) with a duration from January 2013 to December 2016.

The authors also want to extend their thanks to "Federico God ed" Chair of the Spanish Nuclear Council (CSN) at the Universidad Politécnica de Madrid for their complementary support for the development of this project.

Dr. Michele Andreani (PSI) is gratefully acknowledged for the helpful and stimulating discussions on the PAR behaviour and modelling requirements.

\section{References}

Andreani, M., Badillo, A., Kapulla, R., Smith, B., 2015. Synthesis of the OECD/NEA-PS CFD Benchmark Exercise. In: Proceedings of the 16th International Topical Meeting on Nuclear Reactor Thermalhydraulics (NURETH-16), Chicago, IL, USA August 30 - September 4, Paper 13585.

AREVA Passive Autocatalytic Recombiner, 2011. Hydrogen Control and Mitigation for Combustible Gas Control. http://us.areva.com/home/liblocal/docs/Solutions/ literature/PAR\%20Passive\%20Autocatalyic\%20Recombiner.pdf.

Bachellerie, E., Arnould, F., Auglaire, M. de Boeck, B., Braillard, O, Eckardt, B. Ferroni, F., Moffett, R., 2003. Generic approach for designing and implementing a passive autocatalytic recombiner PAR-system in nuclear power plant containments. Nucl. Eng. Des. 221, 151-165.

Bocanegra, R. Jimenez, G., Fernández-Cosials, K., 2016. Development of a PWR-W GOTHIC 3D model for containment accident analysis. Ann. Nucl. Energy 87 547-560.

Breitung, W., 1997. The Analysis of Hydrogen Behaviour in Severe Accidents. Lecture 11. Eurocourse.

Breitung, W., Royl, P., 2000. Procedure and tool for deterministic analysis and control of hydrogen behaviour in severe accidents. Nucl. Eng. Des. 202, 249268.

Chen, Yen-Shu, Yuann, Yng-Ruey, Dai, Liang-Che, Lin, Yon-Pon, 2011. Pressure and temperature analyses using GOTHIC for Mark I containment of the Chinshan Nuclear Power Plant. Nucl. Eng. Des. 241, 1548-1558.

Chen, Yen-Shu, Yuann, Yng-Ruey, Dai, Liang-Che, 2012. Lungmen ABWR containment analyses during short-term main steam line break LOCA using GOTHIC. Nucl. Eng. Des. 247, 106-115.

(Dewit, W.A., Koroll, G.W., and Loesel Sitar, J., Graham, W.R.C., 1996. Hydrogen Recombiner Development at AECL. In: OECD Workshop on the Implementation of Hydrogen Mitigation Techniques, 297-134, AECL-11762, NEA/CSNI/R(96)8, Winnipeg (Manitoba) Canada, 13-15 May.

Dimmelmeier, H., Eyink, J., Mohaved, M.A., 2012. Computational validation of the EPR $^{\mathrm{TM}}$ combustible gas control system. Nucl. Eng. Des. 249, 118-124.

GOTHIC Thermal Hydraulic Analysis Package, 2014. Version 8.1(QA). September 2014. EPRI, Palo Alto, CA.

Fernández-Cosials, K., Jimenez, G., Lopez-Alonso, E., 2015. Analysis of a gas stratification break-up by a vertical jet using the GOTHIC code. Nucl. Eng. Des. 297, 123-135.

Grgić, D., Simic, Z., Glaser, B., 2012. Prediction of Local Hydrogen Concentrations in PWR Containment Using GOTHIC Code. Trans. Am. Nucl. Soc. 106, 1032-1035.

Grgić, D., Fancev, T. and Sadek, S., 2014. Calculation of hydrogen concentration in containment during LOCA accident. Zadar (Croatia). In: Proceedings of the 10th International Conference on Nuclear Option in Countries with Small and Medium Electricity Grids.

Grgić, D., Fancev, T., Sadek, S. and Bencik, V., 2014. Spatial Distribution of Hydrogen in NEK Containment. Portoroz (Slovenia). In: 23rd International Conference Nuclear Energy for New Europe.

Office for Nuclear Regulation An agency of HSE, 2011. Generic Design Assessment New Civil Reactor Build. Step 4 Fault Studies - Containment and Severe Accident Assessment of the EDF and AREVA UK EPR ${ }^{\mathrm{TM}}$ Reactor. ONR-GDA-AR-11020b, Rev. 0.

Office for Nuclear Regulation An agency of HSE, 2013. Generic Design Assessment New Civil Reactor Build. GDA Close-out for the EDF and AREVA UK EPR ${ }^{\mathrm{TM}}$ Reactor GDA Issue GI-UKEPR-RC-01 Revision 1 - Combustible Gas Control Systems. ONR-GDA-AR-12-019, Rev. 0.

IAEA TECDOC-1661, 2011. Mitigation of Hydrogen Hazards in Severe Accidents in Nuclear Power Plants. International Atomic Energy Agency, Vienna, p. 2011.

Jimenez, G., Serrano, C., Lopez-Alonso, E., Molina, M.C., Calvo, D., Garcia, J., Queral, C., Zuriaga, J.V., González, M., 2015. BWR Mark III containment analyses using a GOTHIC 8.0 3D model. Ann. Nucl. Energy 85, 687-703.

Kljenak, I., Bentaib, A., Jordan, T., 2012. Nuclear Safety in Light Water Reactors Chapter 3.1 Baj Raj Seghal. Academic Press.

SOAR on Containment thermal-hydraulics and Hydrogen Distribution. OECD-NEA 1999

THAI Project. Hydrogen and Fission Product Issues. Relevant for Containment Safety Assessment under Severe Accident Conditions, 2010. Final Report. NEA/CSNI/R, 3.

Status Report on Hydrogen Management and Related Computer Codes. OECD-NEA 2015.

Ozdemir, O.E., George, T., 2015a. BWR MARK I pressure suppression pool mixing and stratification analysis using GOTHIC lumped parameter modelling methodology. Ann. Nucl. Energy 85 (2015), 532-543. 
Ozdemir, O.E., George, T.L., Marshall, M.D., 2015b. Fukushima Daiichi Unit 1 power plant containment analysis using GOTHIC. Ann. Nucl. Energy 85 (2015), 621632.

Papini, D., Grgić, D., Cammi, A., Ricotti, M.E., 2011. Analysis of different containment model for IRIS small break LOCA, using GOTHIC and RELAP5 codes. Nucl. Eng. Des. 241, 1152-1164.

Papini, D., Steiner, P., Andreani, M., Ničeno, B., Klügel, J.-U. and Prasser, H.-M., 2015 Simulation of the hydrogen distribution in a power plant using the GOTHIC code. In: Proceedings of the 7th European Review Meeting on Severe Accident Research (ERMSAR-2015) Marseille, France, March 24-26.

Papini, D., Steiner, P., Andreani, M., Ničeno, B., Klügel, J.-U. and Prasser, H.-M., 2015 Simulation of Hydrogen Distribution in the Containment during a Severe Accident with fast Hydrogen-Steam release. In: Proceedings of the 16th International Topical Meeting on Nuclear Reactor Thermalhydraulics (NURETH-16), Chicago, IL, USA, August 30-September 4, Paper 13337.

Royl, P., Rochholz, H., Breitung, W., Travis, J.R., Necker, G., 2000. Analysis of steam and hydrogen distributions with mitigation in NPP containments. Nucl. Eng. Des. 202, 231-248.

Serrano, C. Jimenez, G. Molina, M.C., López-Alonso, E., Justo, D., Zuriaga, J.V., González, M., 2016. Proposed methodology for Passive Autocatalytic
Recombiner sizing and location for a BWR Mark-III reactor containment building. Ann. Nucl. Energy (in Press).

Shapiro, Z.M., Mofette, T.R., 1957. Hydrogen Flammability Data and Application to PWR Loss Of Coolant Accident, Bettis Plant, Pittsburgh, WAPD-SC-545.

Sandia National Laboratory, 2015. MELCOR Computer Code Manual SAND2015-691 R. Volume 1: Primer and User's Guide.

Szabó, T., Benz, S., Kretzschmar, F., Royl, P., Jordan, T., 2012. Prediction of Hydrogen Distribution Under Severe Accident Conditions with CFD and Lumped Parameter Codes, ICONE2012-54499. In: Proceedings of the 20th Int. Conf. on Nuclear Engineering, Anaheim, CA, USA.

Szabó, T., Kretzschmar, F., Schulenberg, T., 2014. Obtaining a more realistic hydrogen distribution in the containment by coupling MELCOR with GASFLOW. Nuclear Engineering and Design 269, 330-339.

Visser, D.C., Agostinelli, G., Siccama, N.B., and Komen, E.M.J., 2013. Hydrogen risk assessment - Hydrogen distribution and mitigation. In: Proceedings of the 15th International Topical Meeting on Nuclear Reactor Thermalhydraulics (NURETH15), Pisa, Italy, May 12-17, Paper NURETH15-489.

Xiao, J., Travis, J.R., Royl, P., Necker, G., Svishchev, A., Jordan, T., 2016. 3D all-speed CFD code for safety analysis of nuclear reactor containment: Status of GASFLOW parallelization, model development, validation and application. Nucl. Eng. Des. $301,290-310$. 